Original Research Paper

\title{
Optical and Structure Analysis of ZnO:Al Film
}

\author{
${ }^{1,2}$ Neilo Marcos Trindade, ${ }^{3}$ Michel Chaves, ${ }^{3}$ José Roberto Ribeiro Bortoleto, \\ ${ }^{4}$ Américo Sheitiro Tabata and ${ }^{4}$ José Humberto Dias da Silva \\ ${ }^{I}$ Departament of Physics, Federal Institute of Education, Science and Technology of São Paulo - IFSP, São Paulo, Brazil \\ ${ }^{2}$ Institute of Physics, University of São Paulo - USP, São Paulo, Brazil \\ ${ }^{3}$ Science and Technology Institute, São Paulo State University-UNESP, Sorocaba, SP, Brazil \\ ${ }^{4}$ Departament of Physics, São Paulo State University-UNESP, Bauru, SP, Brazil
}

Article history

Received: 01-09-2017

Revised: 7-09-2017

Accepted: 18-09-2017

Corresponding Author: Neilo Marcos Trindade Physics, Federal Institute of Education, Science and Technology of Sao Paulo, Brazil

Email: ntrindade@ifsp.edu.br

\begin{abstract}
ZnO}$ and $\mathrm{ZnO}: \mathrm{Al}$ are wide-bandgap semiconductors which have many applications, mainly as transparent conducting films. Thin films of these compounds were deposited onto glass and silicon substrates by RF magnetron sputtering for the investigation of structural and optical characteristics. The XRD results show that the films present wurtzite structure. The formation of a polycrystalline film having a preferential crystallographic orientation in the plane (002) is observed in the doped samples. The Al incorporated films exhibited optical transmittance above $80 \%$ in the visible spectrum and a clear absorption band in the infrared due to free carriers. Additionally, the optical band gap around $3.48 \mathrm{eV}$ is significantly above the values for the intrinsic $\mathrm{ZnO}(3.25 \mathrm{eV})$. Photoluminescence (PL) measurements showed a broad emission band in the visible region. In addition, PL emission lines at 3.32 and $3.37 \mathrm{eV}$ showed up in $\mathrm{Al}$ incorporated films, and were related to excitonic emissions. The results show that the Burstein-Moss effect plays a central role in determining the optical characteristics of the doped material.
\end{abstract}

Keywords: Zinc Oxide, AZO, Burstein-Moss

\section{Introduction}

Films produced from doped metal oxides can have an excellent combination of optical transparency and electrical conductivity. These materials, called Transparent Conducting Oxides (TCOs), are fundamental components in different optoelectronic devices due to the ability to couple an optical transmittance of around $80 \%$ in the visible region and low electrical resistivity around $10^{-3}$ to $10^{-4} \Omega . \mathrm{cm}$ (da Silva et al., 2014). Recently, the TCOs films have attracted scientific and technological interest because of their potential application in illuminated panels, solar cells (Park et al., 2001; Alia et al., 2005); optical windows in residential, automotive (Sundaram and Khan, 1997) and gas sensors (Sahu and Huang, 2006). From a commercial standpoint, the most widely used has been indium tin oxide $\left(\operatorname{In}_{2} \mathrm{O}_{3}: \mathrm{Sn}\right)$, commonly known as ITO, especially in applications of various types of Liquid Crystal Displays (LCD) (Minami, 2008). However, due to the scarcity of indium, ITO generates a high production cost (Klingshirn, 2007). $\mathrm{ZnO}$ is one of the most promising candidates to replace ITO because of its low toxicity, availability and low production cost. It can also be produced on a large scale and presents high stability in the hydrogen plasma and thermal cycles used in the production device (Sahu and Huang, 2006; Das and Ray, 2003; Lin et al., 2011; Tohsophon et al., 2011).

There are several articles reporting advances in the synthesis and application of semiconductor thin films based on $\mathrm{ZnO}$ with great potential for the replacement of ITO, in addition to optoelectronics applications (Pla et al., 2003; Ong et al., 2005), such as Organic Light Emitting Diodes (OLED), transistors, solar cells and non-volatile memories (Song et al., 2013). In particular, as solar cells, it has grown into application areas that need low-power, for example, those related to telecommunications, maritime signaling and land, rural electrification, etc. (Lunas, 2009). The quality of the solar cells strongly depends on the quality of the TCO films, requiring rough surfaces and resistivity in the range of $1-5 \times 10^{-4} \Omega . \mathrm{cm}$ and good optical properties (Tohsophon et al., 2011). Other applications include $\mathrm{ZnO}$ acoustic wave devices (Melloch and Wagers, 1983), heat reflectors (Das and Ray, 2003) and gas sensors (Ushio et al., 1994). In the ultraviolet spectral range, $\mathrm{ZnO}$ has also been used as an emitting material in the blue band in the visible (Bixia et al., 2001).

To reduce the electrical resistivity of this material different types of dopants have been used in Groups III and IV, such as B, Ge, Ti, Al, Ga, In, rare earth (Ferreira, 
2008). The $\mathrm{Al}^{3+}$ ions $(0.54 \AA)$ and $\mathrm{Ga}^{3+}(0.62 \AA)$ are considered the best dopants because they have ionic radii close to the radius of the ion $\mathrm{Zn}^{2+}(0.74 \AA)$ (Ferreira, 2008). The doping of $\mathrm{ZnO}$ by $\mathrm{Al}$ atoms occurs by substitution of an $\mathrm{Al}$ atom by a $\mathrm{Zn}$ atom in its hexagonal lattice. It can also be done by migration of $\mathrm{Al}$ to a noncrystalline region of the grain boundaries, forming links between Al-O. Most of these atoms can replace $\mathrm{Zn}^{2+}$ by ionizing to $\mathrm{Al}^{3+}$. Thus, the aluminum atoms play important role in the crystal lattice, acting as substitutes ions. Consequently, a free electron is likely to be present for each substitutional of $\mathrm{Al}$ atom (Yu et al., 2005).

As a conductive transparent oxide, $\mathrm{ZnO}$ doped with $\mathrm{Al}$ [also found in the literature as AZO (Al-doped $\mathrm{ZnO})$ ] shows great promise for applications such as emitters in the range $\mathrm{UV} / \mathrm{blue}$, photodetectors, and transparent electronics (Bixia et al., 2001). Applications such as solar cells had already been reported in the 90's using zinc oxide doped with aluminum with properties superior to zinc oxide doped with indium in terms of resistivity and transparency (Harding et al., 1991; Martínez et al., 1997). Later, its chemical (Yoo et al., 2005) and thermal stability differential during processing (Mosbah and Aida, 2012) was also reported. Other features, which promote its use, are its constituents $\mathrm{Zn}$ and $\mathrm{Al}$, which are more abundant and less toxic than the constituents of ITO (Klingshirn, 2007).

In the present investigation the main objective was to compare the structural and optical properties of transparent and conductive films of $\mathrm{ZnO}$ and $\mathrm{ZnO}: \mathrm{Al}$. This study also sought to identify the conse-quences of the Burstein-Moss effect in the analyzed TCOs, in particular in relation to optical bandgap.

\section{Materials and Methods}

The synthesis of $\mathrm{ZnO}$ and $\mathrm{ZnO}: \mathrm{Al}$ thin films used disc-shaped $\mathrm{Zn}$ and $\mathrm{ZnAl}$ metallic targets, 99.99\% purity, with diameters of $75 \mathrm{~mm}$ and $2 \mathrm{~mm}$ thickness. The deposition system consists of a cylindrical 304 stainless steel chamber of $270 \mathrm{~mm}$ diameter and $200 \mathrm{~mm}$ in height. The partial pressure of oxygen and argon were set at a ratio of 1:10. The total pressure was kept at 10 mTorr, and the depositions lasted 20 minutes. Films were deposited on $1 \mathrm{~mm}$-thick glass substrates by RF magnetron sputtering with the plasma source maintained at a frequency of $13.56 \mathrm{MHz}(\mathrm{RF})$ and power of $100 \mathrm{~W}$. A substrate tem-perature of $373 \mathrm{~K}$ was maintained during the growth. In order to produce $\mathrm{ZnO}: \mathrm{Al}$, the target composition consisted of $98 \mathrm{wt} \%$ zinc and 2 wt.\% aluminum. The choice of $2 \mathrm{wt} . \% \mathrm{Al}$ doping of $\mathrm{ZnO}$ was due to studies reported by other authors (Das and Ray, 2003; Mosbah and Aida, 2012; Kwak, 2004; Dao et al., 2009), regarding this composition as the best condition for a low resistivity ( $\rho \sim 10^{-4} \Omega . \mathrm{cm}$ ) for this type of film. Glass $(25 \times 40 \mathrm{~mm})$ and $(001)$ silicon $\left(100 \mathrm{~mm}^{2}\right)$ substrates were cleaned using detergent (Det Limp S32), deionized water and isopropyl alcohol in ultrasound baths before loading onto the sample holder.

The measurements of X-Ray Diffraction (XRD) were performed employing an X-ray diffractometer (PanalyticalX'Pert Powder) with $\mathrm{CuK}_{\alpha}$ radiation wavelength equals $1.5405 \AA$, allowing the identification of the structure, the crystal orientation and average crystallite size. The geometry used was 2 theta (grazing angle) and a scanning speed of $0.01^{\circ} \mathrm{s}^{-1}$ at an incident angle of $2^{\circ}$ and the scanning range was $20-90^{\circ}$. By using the XRD data, one can estimate the values of the crystallite size by the Scherrer equation (Jiang et al., 2009; Chaves et al., 2013):

$$
\chi=\frac{0.9 \lambda}{\beta \cos \theta}
$$

where, $\lambda, \theta$ and $\beta$ are respectively the wavelength of the $\mathrm{X}$-ray Bragg angle related to study diffraction peak and the half width of this peak.

Optical transmittance and reflectance technique UVVis-NIR was used in the optical characterization. The optical transmittance spectra were measured in a Perkin Elmer Lambda 1050 spectrophotometer. The investigated range was 250 to $2500 \mathrm{~nm}$ with a resolution of $0.05 \mathrm{~nm}$ in the visible region and $0.2 \mathrm{~nm}$ in the infrared region. The transmittance and reflectance spectra data were treated in a computational routine based on Cisneros method (Cisneros, 1998), which allowed the calculations of sample thickness, refractive index, extinction and absorption coefficients. The optical band gap of the materials was used by the following recurrent expression for direct band gap semiconductors (Pankove, 1971; Yu and Cardona, 2010):

$$
a h v=A\left(h v-E_{g}\right)^{112}
$$

Where:

$a=$ The absorption coefficient

$h v=$ The photon energy

$E_{g}=$ The bandgap

$A=$ A constant

A is related to the effective masses of electrons and holes, but in practice also reflects the crystallographic quality of the material (Pankove, 1971; Yu and Cardona, 2010).

Photoluminescence (PL) spectroscopy was carried out at $10 \mathrm{~K}$, by using a cold finger cryostat cooled by helium flow. The excitation source of the samples was provided by the $325 \mathrm{~nm}$ line of a Kimmon HeliumCadmium laser. A Spex 1780 monocromator (controlled by a PC) with a diffraction grating of $600 \mathrm{gr} / \mathrm{mm}$ and blaze of $1.0 \mu \mathrm{m}$ was used to collect the PL signal. A 
Peltier cooled RCA GaAs photo-multiplier mounted at the exit slit of the monochromator detected the signal after optical dispersion. A digital Keithley 617 electrometer was used to read the signal and to send it to a PC. The laser line was focalized in the sample's surfaces and the PL emission was collected by a lens and focalized at the entrance slit of the monochromator.

\section{Results and Discussion}

At room temperature $\mathrm{ZnO}$ is found in the wurtzite structure, which is thermodynamically more stable (Peres, 2007). The unit cell has two external lattice parameters: the basal plane (a) and uniaxial plane (c) and an internal parameter $u$, which describes the cation and anion positions relative to the $z$ axis (Jaffe and Hess, 1993; Marana et al., 2008). The $\mathrm{ZnO}$ wurtzite structure belongs to the space group P63mc with a Bravais lattice ( $a=3.250 \AA$ and $c=5.207 \AA$ and internal coordinate $u=$ 0.382) (Decremps et al., 2003) and can be depicted as a zinc atom surrounded by four oxygen atoms with $\mathrm{sp}^{3}$ hybridization in a tetrahedron configuration along the caxis. In the $\mathrm{ZnO}$ this value is close to a hexagonal cell with a notional value of the c/a ratio of 1.633 (Morkoç and Özgür, 2009).

The samples showed the formation of a polycrystalline film having a preferential crystallographic orientation in the plane (002), shown in Fig. 1. This indicates that the orientation film grows along c-axis, the direction [001] and perpendicular to the substrate surface (Zhang et al., 2002; Kuchiyama et al., 2011; Tang et al., 2013).

This growth characteristic along the c-axis is associated with the lowest free energy referred to the plan (002) (Fujimura et al., 1993). In the first stage of growth of the film, certain grains with particular orientation start growing; coalescence and thermodynamic orientation of the c-axis are achieved (Park et al., 1997).

The $\mathrm{ZnO}$ and $\mathrm{ZnO}: \mathrm{Al}$ films in addition to presenting a preferential peak in the plane (002) also exhibit the presence of the planes (100), (101), (102), (110) and (103), indicating that there was little formation of crystalline structure in other crystallographic directions of $\mathrm{ZnO}$. The XRD results show that $\mathrm{Al}$ doped $\mathrm{ZnO}$ does not alter the structural characteristics, since the most intense peaks of the doped sample show up in positions very close to the ones noticed in undoped samples. The Bragg angles, intensities, full width at half maximum (FWHM) and crystallite size estimated using Scherrer's formula for the (002) planes of the samples are listed in Table 1.

The results of the Table 1 show that there is a variation $\sim 0.8^{\circ}$ at the peak position (002) between the pure sample and the doped sample with $\mathrm{Al}$, a consequence of decrease in the lattice parameter $c$, This change in position is due to the difference between the ionic radius of $\mathrm{Zn}^{2+}(0.74 \AA)$ and $\mathrm{Al}^{3+}(0.54 \AA)$, causing tensions that consequently change the lattice parameters, indicating that the $\mathrm{Al}$ atoms replace $\mathrm{Zn}$ sites (Jiang et al., 2009; Park et al., 1997; Ellmer et al., 2007; Lin et al., 2010).

It is observed in doped sample with $\mathrm{Al}$ that the peak is more intense and the FWHM has a lower value when compared to the pure sample. Therefore, this indicates an improved crystallinity and, for the same preparation conditions, the crystallite size of the $\mathrm{ZnO}$ : $\mathrm{Al}$ is bigger than that of $\mathrm{ZnO}$ (Ma et al., 1996). The FWHM of the peak (002) was used to estimate the average size of crystallite along the c-axis by the Scherrer equ-ation. The results show that there is an increase in crystallite size when comparing doped $(\sim 14 \mathrm{~nm})$ with the undoped sample $(\sim 10 \mathrm{~nm})$. The value of stresses is calculated using equation based on the lattice parameter and is negative because are tensile in a direction of the c-axis. The increase in stress is expected in doped films since the presence of dopant atoms causes an increase in crystal lattice disorder. During the growth of the film this disorder is also generated due to defects, known with intrinsic stress. These deformations increase the energy gap in the case of compressions (Dimova-Malinovska et al., 2008). We observed that there is an increase in the size of the crystallite accompanied by an increase in stress under the same growth conditions, but because it is two samples, further investigation is necessary.

The dependence of spectral transmittance and refletance of the $\mathrm{ZnO}$ and $\mathrm{ZnO}: \mathrm{Al}$ deposited on a glass substrate is shown in Fig. 2. Firstly, the values of the thickness and refractive index for the samples were calculated from the transmittance and reflectance data for $\lambda=550 \mathrm{~nm}$ by the Cisneros method (Cisneros, 1998). The results are shown in Table 2. The obtained values of thickness show that the films presented nanometric character. There is no significant correlation between the refractive index of the doped and pure sample.

A transmittance above $80 \%$ can be observed in the visible spectral region for all films.

In the range below the wavelength around $400 \mathrm{~nm}$ corresponds to energies greater than or equal to the energy value of the band gap. The strong absorption observed in the near ultraviolet region is typical of interband transition (valence-conduction) in broadband semiconductors. In the visible range, the high transmittance is related to the lack of allowed interband transitions and to frequencies much higher than the plasma frequency of the free carriers. However, a gradual decrease in transmittance can be observed in the infrared region, which is related to the metallic character of the free electrons in the conduction band (Nsimama and Samiji, 2012). 


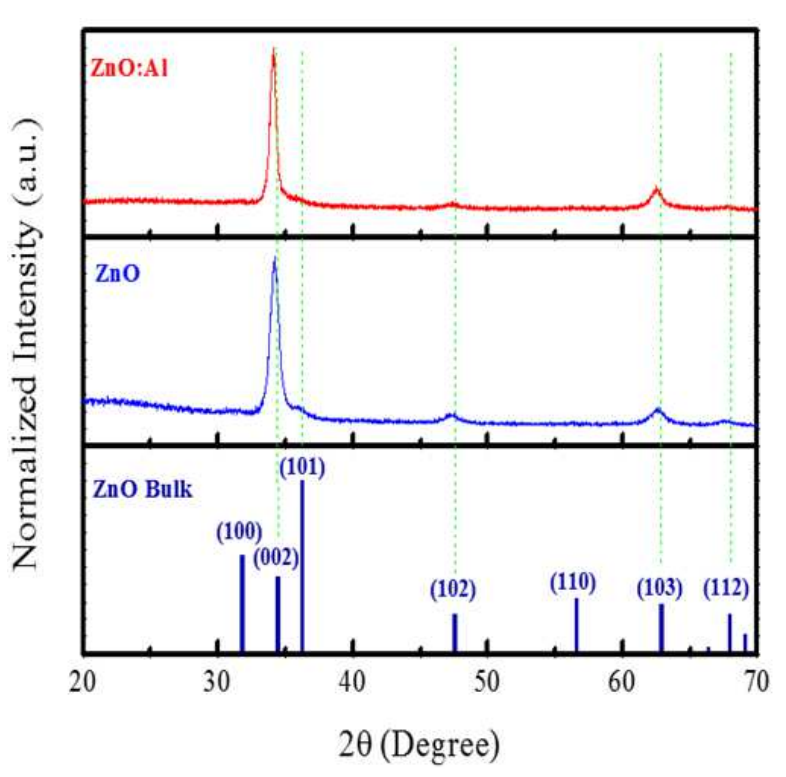

Fig. 1. XRD patterns of the $\mathrm{ZnO}$ and $\mathrm{ZnO}: \mathrm{Al}$ films deposited onto glass substrates

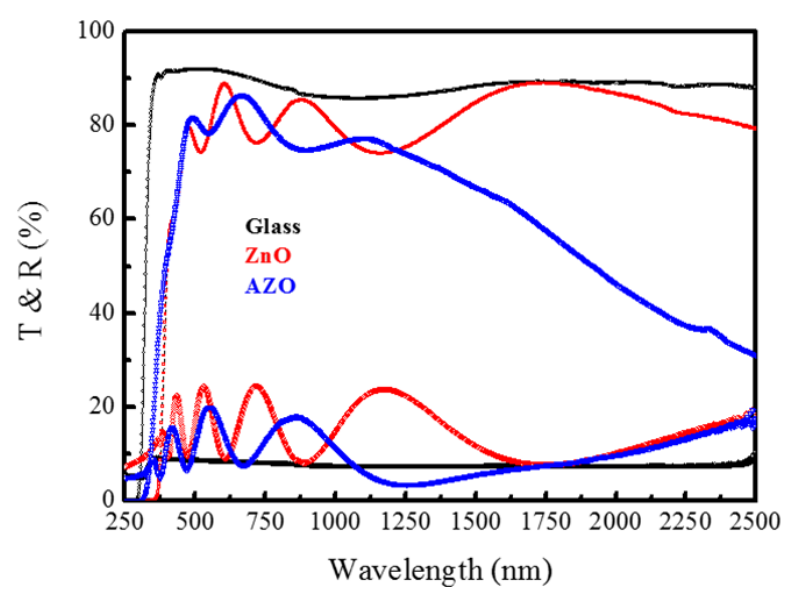

Fig. 2. Optical transmittance (a) and reflectance (b) of glass substrate and films obtained

Table 1. Measurements of the peak (002) angle, intensity, FWHM, and crystallite size

\begin{tabular}{lllllll}
\hline & $\begin{array}{l}\text { Peak } \\
(002)\end{array}$ & $\begin{array}{l}\text { Intensity FWHM } \\
(002)\end{array}$ & $\begin{array}{l}\text { Crystallite } \\
(002)\end{array}$ & $\begin{array}{l}\text { Lattice } \\
\text { Size }\end{array}$ & $\begin{array}{l}\text { Stress } \\
\text { Parameter }\end{array}$ \\
& $2 \theta\left(^{\circ}\right)$ & $(\mathrm{cps})$ & $\left.{ }^{\circ}\right)$ & $(\mathrm{nm})$ & $\mathrm{c}(\mathrm{nm})$ & $(\mathrm{GPa})$ \\
\hline Sample & 34.1948 & 1587 & 0.8118 & 10.2 & 0.5240 & -1.47 \\
ZnO Undoped & 34.0814 & 2943 & 0.5877 & 14.13 & 0.5256 & -2.19 \\
ZnO:Al & & & & 0.5207 & \\
JCPDS 36-1451 & 34.42 & & & &
\end{tabular}

Table 2. Values of the thickness and refractive index for the samples, calculated from the transmit-tance and reflectance data for $\lambda=550 \mathrm{~nm}$ by the Cisneros method (Cisneros, 1998)

\begin{tabular}{llll}
\hline Sample & $\begin{array}{l}\text { Substract refractive } \\
\text { index (u.a.) }\end{array}$ & $\begin{array}{l}\text { Film refractive } \\
\text { index (u.a.) }\end{array}$ & $\begin{array}{l}\text { Thickness } \\
(\mathrm{nm})\end{array}$ \\
\hline $\mathrm{ZnO}$ & 1.58 & 2.02 & 454 \\
$\mathrm{ZnO}: \mathrm{Al}$ & 1.54 & 1.93 & 367 \\
\hline
\end{tabular}

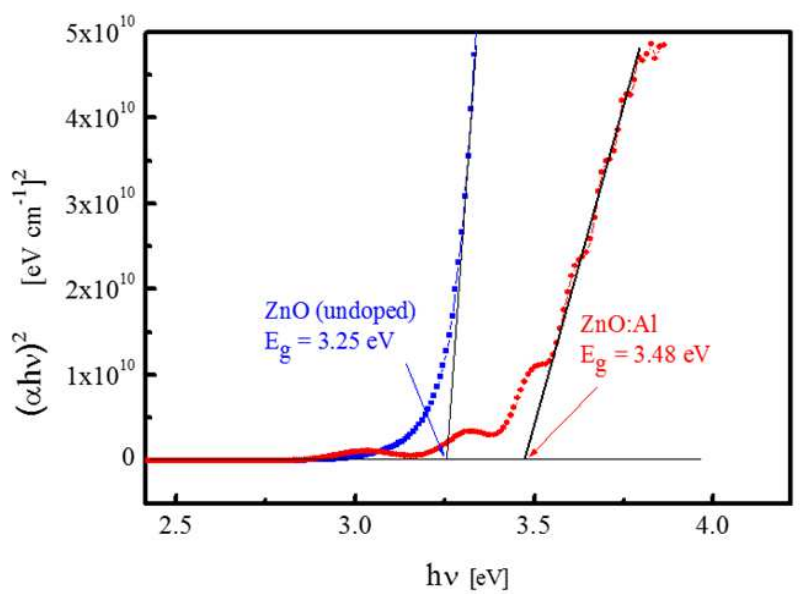

Fig. 3. Absorption edges of $\mathrm{ZnO}$ and $\mathrm{ZnO}: \mathrm{Al}$ samples, calculated using the procedure for direct bandgap materials.

The classical free electron Drude model can be used, together with the spectral response, to estimate the carrier concentration on the conduction band. In the context of this model, the plasma frequency $\left(\omega_{\mathrm{p}}\right)$ divides the spectrum in highly reflecting and low transmitting (frequencies smaller than $\omega_{\mathrm{p}}$ ) and low reflecting and transparent (frequencies bigger than $\omega_{\mathrm{p}}$ ). In the Drude model $\omega_{\mathrm{p}}$ is proportional to the square root of the carrier concentration (Rahmane et al., 2015), so it can explain the increase in $\mathrm{T}$ at higher frequencies if the carrier concentration is sufficiently low. In quantum mechanical terms, the electronic oscillations provided described by the classical model are equivalent to intraband transitions of electrons in the conduction band. So, the transmittance window in the visible range is limited by interband transitions at higher energies and intraband transitions at lower energies.

The effect of conduction band filling by free electrons can be noted on the absorption edge. Fig. 3 shows the bandgap determination plots for the undoped and $\mathrm{Al}$ doped films, where bandgap shift due to doping is clear. The absorption coefficients were calculated using the transmittance of the films and substrates and the Cisneros procedure method for thin films onto weakly absorbing substrates.

For $\mathrm{ZnO}$ films doped with aluminum, values of the optical band gaps in the $3.50 \mathrm{eV}$ energy range were obtained above the intrinsic $\mathrm{ZnO}$ ones. The displacement of the energy of the optical gap is associated with the Burstein-Moss effect presented by Burstein (1954) (Burstein, 1954). According to the literature ( $\mathrm{Lu}$ and Fujita, 2007), in heavily doped n-type semiconductors electrons occupy states at the bottom of the conduction band and Fermi energy moves into the conduction band. Due to the excursion of Fermi level, optical interband transitions can only occur to photons that can make 
vertical transitions from the valence band to a state above the Fermi energy in the conduction band ( $\mathrm{Lu}$ and Fujita, 2007). Therefore, the optical absorption edge shifts to higher energy and the optical energy gap increases. In the infrared region, the doped sample showed a high extinction coefficient in relation the pure sample, this indicates that there is a greater quantity of carriers present in the conduction band influenced by the presence of $\mathrm{Al}$ in films, and hence, promoting the occurrence of the Burstein-Moss effect.

The fringes of low energy interference in the curve of the absorption coefficient for the doped film may be related to defects created by the presence of aluminum and investigated by photoluminescence. The photoluminescence spectra of the $\mathrm{ZnO}$ and $\mathrm{ZnO}: \mathrm{Al}$ films measured at $10 \mathrm{~K}$ are displayed in Fig. 4. In the pure compound, a broad visible band with a weak tail to UV is observed. The PL emission related to the $\mathrm{Al}$ incorporated sample display a slightly different line shape in the visible, and a clear pair of narrow bands in the UV (Fig. 4, red curve).

Generally, $\mathrm{ZnO}$ emission bands can be separated into two parts: (i) UV exciton bands and (ii) visible defect bands. The exact origin of the defect emission band in $\mathrm{ZnO}$ is not well understood and has been the subject of various interpretations, such as oxygen vacancies, zinc interstices, $\mathrm{Zn}$ antisites, extrinsic impurities and complex defects (Bixia et al., 2001; Martins, 2012; Das and Mondal, 2014). Previous reports indicate that the radiative lifetime of ex-citons pure $\mathrm{ZnO}$ is in the nanosecond range, while in the visible range the lifetime of the emission is longer, i.e., in the range of microseconds, so this justifies the emission is stronger in the visible (Das and Mondal, 2014). However, the complex dependence of UV and visible emission intensities is still subject of controversy in the literature (Mohanta, 2014; Manzano et al., 2011; Khan et al., 2013).

The UV band emission is dominated by excitonic transitions (Bixia et al., 2001; Das and Mondal, 2014). According to Das and Mondal (2014) the appearance of the band around $3.35 \mathrm{eV}$ is related to exciton emission or emission qua-si-band, that is, the photo-excited electrons recombine with holes in the valence band or traps near the valence band, considering that this is a value below the gap for pure $\mathrm{ZnO}$.

In the UV range the emission lines showed the highest intensity around $3.32 \mathrm{eV}$ and $3.37 \mathrm{eV}$ (Fig. 4). The emission line at $3.32 \mathrm{eV}$ occurs in a spectral region where the appearance is expected emissions related to Two Electrons Satellites (TES) exciton bound donors (Djurisic and Leung, 2006; Meyer et al., 2004). The emission line in the range of 3.37 to $3.35 \mathrm{eV}$ is correlated emissions bounded excitons (Klingshirn, 2007) and by restricting the range of 3.37 to $3.36 \mathrm{eV}$ these excitons are linked to donor atoms $\left(\mathrm{D}^{+} \mathrm{X}, \mathrm{D}^{0} \mathrm{X}\right)$.

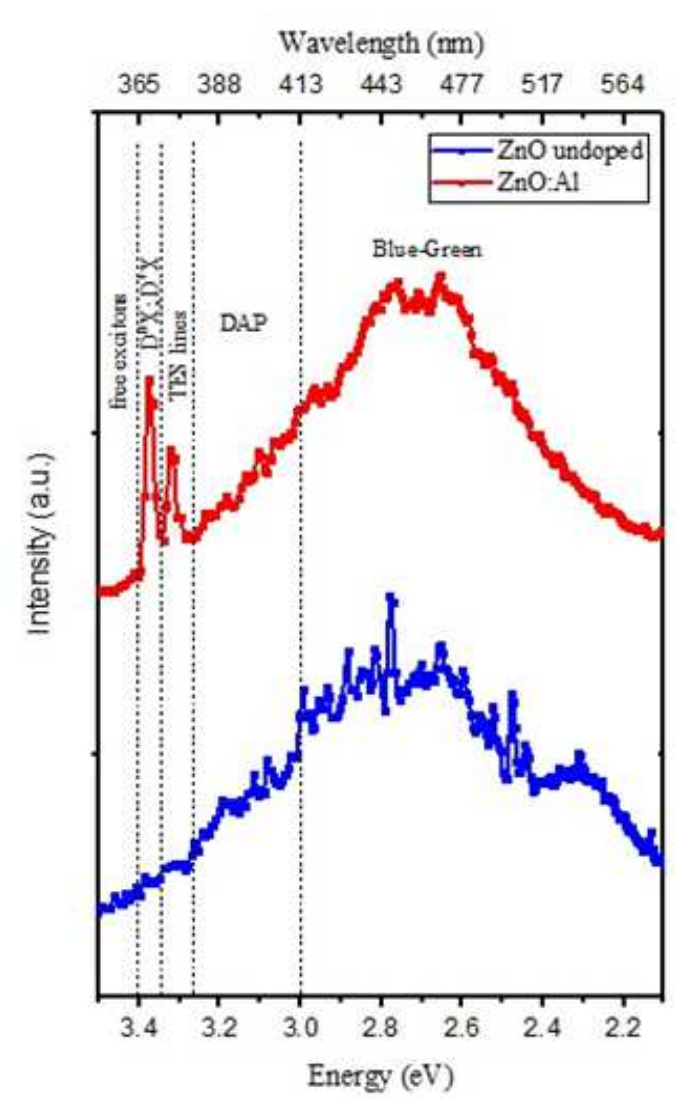

Fig. 4. Photoluminescence of $\mathrm{ZnO}$ and $\mathrm{ZnO}: \mathrm{Al}$ samples deposited on the silicon substrate, at tem-perature $10 \mathrm{~K}$ with excitation source $\lambda=325 \mathrm{~nm}$

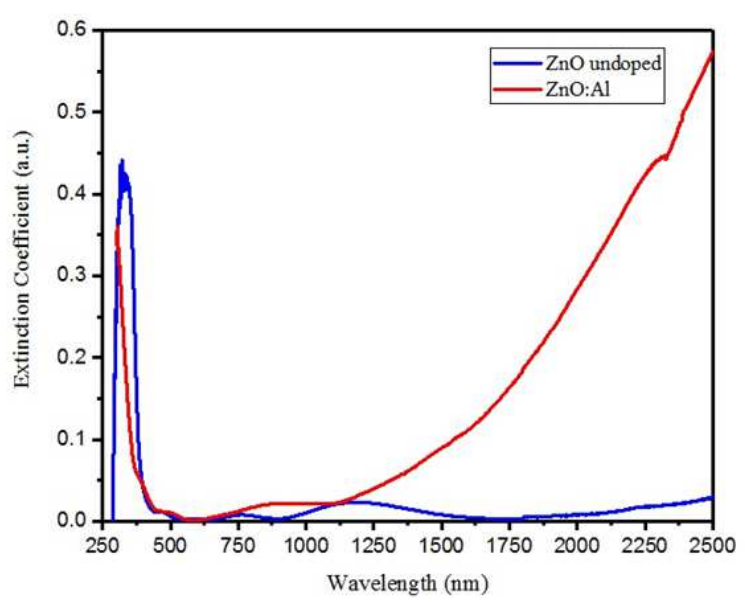

Fig. 5. Variation of the extinction coefficient versus wavelength measurements of $\mathrm{ZnO}$ and $\mathrm{ZnO}: \mathrm{Al}$

The chemical identification of these donors is still unclear (Djurisic and Leung, 2006). Both emission lines present in the PL spectra of our samples; $3.32 \mathrm{eV}$ (Meyer et al., 2004) and $3.37 \mathrm{eV}$ (Peres, 2007) suggest a correlation with the effect of doping $\mathrm{Al}$; since they are not present in the pure sample spectrum. 
Concerning the visible PL emission, Lin et al. (2001) observed the green emission centered at $2.38 \mathrm{eV}$ of the $\mathrm{ZnO}$ film deposited on silicon substrates and suggest that the green emission should correspond to the passage of electrons from the bottom of the conduction band for the level of antisite defects. Recently, $\mathrm{ZnO}$ spectrum was characterized by a green emission band that was associated with a defect level of oxygen vacancy (Mohanta, 2014). Also according to Wang et al. (2011) $\mathrm{ZnO}$ displays two bands centered at 510-540 $\mathrm{nm}$ (green emission) and 600-640 $\mathrm{nm}$ (yellow emission), assigned to oxygen vacancy $\left(V_{\mathrm{o}}\right)$ and interstitial oxygen $\left(O_{i}\right)$, respectively.

According to Das and Mondal (2014), the visible PL emissions from pure $\mathrm{ZnO}$ films prepared by magnetron sputtering, correspond to a broadband coming from a convolution of different transitions that are related to the oxygen vacancy states, $\mathrm{Zn}$ interstitial, doubly ionized $\mathrm{Zn}$ vacancy and oxygen antisite.Due to the different assignments found to the sub-bands of the visible PL emission, it was not possible to attribute a single set of contributions to the observed signal. The difficulty in identifying the origins of emissions-related defects is due to the complexity of microscopic details involved (Das and Mondal, 2014). So, we would rather let them generically attributed to the different kinds of defects, while the narrow UV bands were attributed to Two Electrons Satellites (TES) and excitons are linked to donor atoms $\left(D^{+} X, D^{0} X\right)$.

To complement the results, Fig. 5 shows the extinction coefficient values for the deposited films.

It is observed that the extinction coefficient for the doped and the undoped samples no more than 0.05 to the visible spectrum, with typical extinction coefficients of transparent films. In the infrared region, the doped sample showed a high extinction coefficient before the pure sample, which maintains a value around zero in this range, this indicates that there is a greater quantity of carriers present in the conduction band influenced by the presence of $\mathrm{Al}$ in films, and hence, promoting the occurrence of the Burstein-Moss effect.

\section{Conclusion}

Polycrystalline $\mathrm{ZnO}$ and $\mathrm{ZnO}: \mathrm{Al}$ films were produced (20 min deposition) by RF reactive sputtering using $\mathrm{Zn}$ and $\mathrm{ZnAl}$ targets and $\mathrm{Ar}$ and $\mathrm{O}_{2}$ gas mixtures. The crystallites presented wurtzite structure and a high degree of orientation texture, being the crystallites c-axis preferentially oriented perpendicular to the surfaces of the substrates. The $\mathrm{Al}$ incorporation $(2 \mathrm{wt} . \%)$ has produced significant increases in orientation texture and crystallite sizes. The optical band gap values of the $\mathrm{Al}$ incorporated samples are in the range $3.48 \mathrm{eV}$ that are above the values obtained for $\mathrm{ZnO}$ intrinsic $(3.25 \mathrm{eV})$. The $\mathrm{Al}$ incorporation results in two clear PL excitonic bands in the UV and are in qualitative agreement with the results obtained in the optical absorption coefficient. The extinction coefficient showed a high absorption in the infrared region doped samples compared to the undoped sample, and therefore, confirmed the increased carrier density by doping presence. The optical results show Burstein-Moss as the dominant effect related to $\mathrm{Al}$ incorporation in the films.

\section{Acknowledgement}

The authors would like to thank the financial support of the Brazilian agencies FAPESP (2008/53311-5; 2013/19289-0, 2013/19713-7, 2013/07296-2) and CNPq (555774/2010-4) and Mr. Luciano B. Ramos for language review. The authors would like to thank to Me. Carlos Guilherme Gonçalves de Azevedo by transmittance measurements in the Films Semiconductor Laboratory of São Paulo State University (UNESP).

\section{Author's Contributions}

All the authors contributed equally to prepare, develop and carry out this manuscript.

\section{Ethics}

Authors declare that are not ethical issues that may arise after the publication of this manuscript. This manuscript contains unpublished material.

\section{References}

Alia, H.M., H.A. Mohamed and S.H. Mohamed, 2005. Enhancement of the optical and electrical properties of ITO thin films deposited by electron beam evaporation technique. Eur. Physical J. Applied Physics, 31: 87-93. DOI: 10.1051/epjap:2005044

Bixia, L., F. Zhuxi and J. Yunbo, 2001. Green luminescent center in undoped zinc oxide films deposited on silicon substrates. Applied Physics Lett., 79: 943-945. DOI: 10.1063/1.1394173

Burstein, E., 1954. Anomalous optical absorption limit in InSb. Physical Rev., 93: 632-633.

DOI: 10.1103/PhysRev.93.632

Chaves, M., E.P. da Silva, S.F. Durrant, N.C. da Cruz and P.N. Lisboa-Filho et al., 2013. Effect of Zn sputtering rate on the morphological and optical properties of ZnO films. Mater. Sci. Applic., 4: 802-807. DOI: 10.4236/msa.2013.412102

Cisneros, J.I., 1998. Optical characterization of dielectric and semiconductor thin films by use of transmission data. Applied Optics., 37: 5262.

DOI: 10.1364/AO.37.005262 
da SilvaI, É.P., M. ChavesI, S.F. DurrantI, P.N. LisboaFilhoII, J.R.R. BortoletoI et al., 2014. Morphological and electrical evolution of $\mathrm{ZnO}: \mathrm{Al}$ thin films deposited by RF magnetron sputtering onto glass substrates. Materials Res., 17: 1384-1390. DOI: $10.1590 / 1516-1439.281214$

Dao, V.A., T. Le, T. Tran, H.C. Nguyen and K. Kim et al., 2009. Electrical and optical studies of transparent conducting $\mathrm{ZnO}: \mathrm{Al}$ thin films by magnetron $\mathrm{dc}$ sputtering. J. Electroceram, 23: 356-360.

DOI: $10.1007 / \mathrm{s} 10832-008-9466-6$

Das, D. and P. Mondal, 2014. Photoluminescence phenomena prevailing in c-axis oriented intrinsic $\mathrm{ZnO}$ thin films prepared by RF magnetron sputtering. RSC Advances, 4: 35735-35743. DOI: 10.1039/C4RA06063F

Das, R. and S. Ray, 2003. Zinc oxide- a transparent conducting IR-reflector prepared by rf-magnetron sputtering. J. Phys. D.: Appl. Phys., 36: 152-155.

Decremps F., F. Datchi, A.M. Saitta, A.Polian and S. Pascarelli et al., 2003. Local structure of condensed zinc oxide. Physical Review B. 68: 1098-1121. DOI: 10.1103/PhysRevB.68.104101

Dimova-Malinovska, D., H. Nichev and O. Angelov, 2008. Correlation between the stress in $\mathrm{ZnO}$ thin film and Urbach band trail width. Current Topic Solid State Physics, 10: 3353-3357. DOI: $10.1002 /$ pssc. 200778886

Djurisic, A.B. and Y.H. Leung, 2006. Optical properties of $\mathrm{ZnO}$ nanostructures. Small, 2: 944-961. DOI: $10.1002 /$ smll.200600134

Ellmer, K., A. Klein and B. Rech, 2007. Transparent Conductive Zinc-Oxide: Basics and Applications in Thin Film Solar Cells. 1st Edn., Springer-Verlag, Berlin, pp: 446. ISBN-10: 3540736123

Ferreira, N.S., 2008. Deposição e caracterização de filmes de óxido de zinco dopado com alumínio. [Dissertation]. Rio de Janeiro: Universidade Federal do Rio de Janeiro.

Fujimura, N., T. Nishihara, S. Goto, J. Xu and T. Ito, 1993. Control of preferred orientation for $\mathrm{ZnO}_{\mathrm{x}}$ films: Control of self-texture. J. Crystal Growth, 130: 269-279. DOI: 10.1016/0022-0248(93)90861-P

Harding, G.L., B. Window and E.C. Horrigan, 1991. Aluminium-and indium doped zinc oxide thin films prepared by DC magnetron reactive sputtering. Sol. Energy Mater. Sol. Cells, 22: 69-91.

DOI: 10.1016/0165-1633(91)90007-8

Jaffe, J.E. and A.C. Hess, 1993. Hartree-Fock study of phase-changes in $\mathrm{ZnO}$ at high-pressure. Phys. Review B., 48: 176.

DOI: 10.1103/PhysRevB.48.7903
Jiang, Y.J., D.X. Zhang, H.K. Cai, K. Tao and Y. Xue et al., 2009. Influence of the gas flow of Argon and the distance between substrate and plasma on properties of Al-doped zinc oxide films. J. Physics: Conference Series, 152: 1-7. DOI: 10.1088/1742-6596/152/1/012030

Khan, F., S. Ameen, M. Song and H.S. Shin, 2013. Influence of excitation wavelength on photoluminescence spectra of $\mathrm{Al}$ doped $\mathrm{ZnO}$ films. J. Luminescence, 134: 160-164. DOI: 10.1016/j.jlumin.2012.08.054

Klingshirn, C., 2007. ZnO: From basics towards applications. Phys. Stat. Sol., 244: 3027-3073. DOI: $10.1002 /$ cphc. 200700002

Kuchiyama, T., K. Yamamoto, S. Hasegawa and H. Asahi, 2011. Surface morphology and crystalline structure of high-stable polycrystalline transparent conductive zinc oxide films. Applied Surface Sci., 258: 1488-1490. DOI: 10.1016/j.apsusc.2011.09.112

Kwak, D.J., 2004. Argon gas pressure and substrate temperature dependences of $\mathrm{ZnO}: \mathrm{Al}$ film by magnetron sputtering. J. Korean Physical Society, 45: 206-210.

Lin, B., Z. Fu and Y. Jia, 2001. Green luminescent center in undoped zinc oxide films deposited on silicon substrates. Applied Physics Lett., 79: 943-946. DOI: $10.1063 / 1.1394173$

Lin, S.S. and D.K. Wu, 2010. The properties of Aldoped $\mathrm{TiO}_{2}$ nanoceramic films deposited by simultaneous rf and dc magnetron sputtering. Ceramics Int., 36: 87-91.

DOI: 10.1016/j.ceramint.2009.06.023

Lin, Y.C., B.L. Wang, W.T. Yen and C.H. Shen, 2011. Surface textured molybdenum doped zinc oxide thin films prepared for thin film solar cells using pulsed direct current magnetron sputtering. Thin Solid Films., 519: 5571-5576. DOI: $10.1016 /$ j.tsf.2011.03.014

Lu, J.G. and S. Fujita, 2007. Carrier concentration dependence of band gap shift in $\mathrm{n}$-type $\mathrm{ZnO}: \mathrm{Al}$ films. J. Applied Physics, 101: 083705. DOI: $10.1063 / 1.2721374$

Lunas, F.R., 2009. Caracterização de Filmes Finos de $\mathrm{ZnO}$ Dopados com Al e Mn Depositados em Substrato Vítreo pelo Método Spray Pirólise. [Dissertation]. São Paulo: Universidade Estadual Paulista.

Ma, J., F. Ji, H.L. Ma and S.Y. Li, 1996. Electrical and optical properties of $\mathrm{ZnO}$ : Al films prepared by an evaporation method. Thin Solid Films, 279: 213-215. DOI: 10.1016/0040-6090(95)08173-9

Manzano, C.V., O. Caballero-Calero, B. Alén and M.S. Martín-González, 2011. Synthesis and luminescence properties of eletrodeposited $\mathrm{ZnO}$ films. J. Applied Physics, 110: 043538. DOI: 10.1063/1.3622627 
Marana, N.L., V.M. Longo, E. Longo, J.B.L. Martins and J.R. Sambrano et al., 2008. Electronic and structural properties of the (1010) and (1120) $\mathrm{ZnO}$ surfaces. J. Phys. Chem. A, 112: 8958-8963. DOI: $10.1021 / j p 801718 x$

Martínez, M.A., J. Herrero and M.T. Gutiérrez, 1997. Deposition of transparent and conductive Al-doped $\mathrm{ZnO}$ thin films for photovoltaic solar cells. Sol. Energy Mater. Sol. Cells, 45: 75-86. DOI: 10.1016/S0927-0248(96)00066-9

Martins, R.J., 2012. Controle coerente das bandas de emissão de $\mathrm{ZnO}$ através de algoritmo genético. [Dissertation]. São Carlos: Universidade Federal de São Carlos.

Melloch, M.R. and R.S. Wagers, 1983. Propagation loss of the acoustic pseudosurface wave on $(\mathrm{ZXt}) 45^{\circ}$ GaAs. Appl. Phys. Lett. 43: 1008-1009. DOI: $10.1063 / 1.94224$

Meyer, B.K., H. Alves, D.M. Hofmann, W. Kriegseis and D. Forster et al., 2004. Bound exciton and donor-acceptor pair recombinations in ZnO. Phys. Stat. Sol., 241: 231-260.

DOI: $10.1002 /$ pssb.200301962

Minami, T., 2008. Substitution of transparent conducting oxide thin films for indium tin oxide transparent electrode applications. Thin Solid Films. 516: 1314-1321. DOI: $10.1016 /$ j.tsf.2007.03.082

Mohanta, A., 2014. Effect of pressure and Al doping on structural and optical properties of $\mathrm{ZnO}$ nano-wires synthesized by chemical vapor deposition. J. Luminescence, 146: 470-474.

DOI: $10.1016 /$ j.jlumin.2013.10.028

Morkoç, H. and Ü. Özgür, 2009. Zinc Oxide: Fundamentals, materials and device technology. Wiley-VCH Verlag GmbH \& Co. KGaA.

Mosbah, A. and M.S. Aida, 2012. Influence of deposition temperature on structural, optical and electrical properties of sputtered $\mathrm{Al}$ doped $\mathrm{ZnO}$ thin films. J. Alloys Compounds, 515: 149-153.

DOI: 10.1016/j.jallcom.2011.11.113

N.L. Marana, S. Casassa, E. Longo and J.R. Sambrano et al. Structural, electronic, vibrational and topological analysis of single-walled zinc oxide Nanotubes. J. Phys. Chem. C., 120: 6814-6823.

DOI: 10.1021/acs.jpcc.5b11905

Nsimama, P.D. and M.E. Samiji, 2012. Electrical properties of DC reactive magnetron sputtered ZnO:Al films from optical spectra. Tanzania J. Sci., 38: 39-52.

Ong, K.S., J. Hu, R. Shrestha, F. Zhu and S.J. Chua, 2005. Flexible polymer light emitting devices using polymer-reinforced ultrathin glass. Thin Solid Films, 477: 32-37. DOI: 10.1016/j.tsf.2004.08.107.

Pankove, J.I., 1971. Optical Processes in Semiconductors. Dover Publications. Mineola NY.
Park, K.C., D.Y. Ma and K.H. Kim, 1997. The physical properties of Al-doped zinc oxide films prepared by RF magnetron sputtering. Thin Solid Films, 305: 201-209. DOI: 10.1016/S0040-6090(97)00215-0

Park, S.H., H.M. Kim, B.R. Rhee, E.Y. Ko and S.H. Shon et al., 2001. Effects of oxygen concentration on characteristics of RF-Sputtered In2O3-ZnO thin films. Japanese J. Applied Phys., 40: 1429-1430.

Peres, M.A.B., 2007. Caracterização Óptica de amostras de ZnO. [Dissertation]. Aveiro: Universidade de Aveiro.

Pla, J., M. Tamasi, R. Rizzoli, M. Losurdo and E. Centurioni et al., 2003. Optimization of ITO layers for applications in a-Siyc-Si heterojunction solar cells. Thin Solid Films, 425: 185-192.

DOI: 10.1016/S0040-6090(02)01143-4

Rahmane, S., M.S. Aida, M.A. Djouadi and N. Barreauc 2015. Effects of thickness variation on properties of $\mathrm{ZnO}$ :Al thin films grown by $\mathrm{RF}$ magnetron sputtering deposition. Superlattices Microstructures, 79: 148-155. DOI: 10.1016/j.spmi.2014.12.001

Sahu, D.R. and J.L. Huang, 2006. High quality transparent conductive $\mathrm{ZnO} / \mathrm{Ag} / \mathrm{ZnO}$ multilayer films depo-sited at room temperature. Thin Solid Films. 515: 876-879. DOI: $10.1016 /$ j.tsf.2006.07.049

Song, S., J. Jang, Y. Ji, S. Park and T.W. Kim et al., 2013. Twistable nonvolatile organic resistive memory devices. Organic Electronics, 14: 2087-2092. DOI: 10.1016/j.orgel.2013.05.003

Sundaram, K.B. and A. Khan, 1997. Characterization and optimization of zinc oxide films by r.f. magnetron sputtering. Thin Solid Films. 295: 87-91. DOI: 10.1016/S0040-6090(96)09274-7

Tang, G., H. Liu and W. Zhang, 2013. The variation of optical band gap for $\mathrm{ZnO}$ :In films prepared by sol-gel technique. Advances in Mat. Scie. Eng., 2013: 1-4. DOI: $10.1155 / 2013 / 348601$

Tohsophon, T., N. Wattanasupinyoa, B. Silskulsuka and N. Sirikulratb, 2011. Effect of aluminum and indium codoping on zinc oxide films prepared by DC magnetron sputtering. Thin Solid Films, 520: 726-729. DOI: 10.1016/j.tsf.2011.06.079

Ushio, Y., M. Miyayama and H. Yanagida, 1994. Effects of interface states on gas-sensing properties of a $\mathrm{CuO} / \mathrm{ZnO}$ thin-film heterojunction. Sens. Actuators B Chem., 17: 221-226. DOI: 10.1016/0925-4005(93)00878-3

Wang, T., Y. Liu, Q. Fang, M. Wu and X. Sun et al., 2011. Low temperature synthesis wide optical band gap $\mathrm{Al}$ and (Al, Na) codoped $\mathrm{ZnO}$ films. Applied Surface Sci., 257: 2341-2345. DOI: $10.1016 / \mathrm{j}$. apsusc.2010.09.100 
Yoo, J., J. Lee, S. Kim, K. Yoon and J. Park et al., 2005. High transmittance and low resistive $\mathrm{ZnO}: \mathrm{Al}$ films for thin films solar cells. Thin Solid Films, 480-481: 213-217.

DOI: $10.1016 /$ j.tsf.2004.11.010

Yu, P. and M. Cardona, 2010. Fundamentals of Semiconductors. Springer. Heidelberg, pp: 775.

$\mathrm{Yu}$, X.H., J. Ma and F. Ji, 2005. Effects of sputtering power on the properties of $\mathrm{ZnO}$ : Ga films deposited by r.f. magnetron-sputtering at low temperature. J. Crystal Growth, 274: 474-479.

DOI: $10.1016 /$ j.jcrysgro.2004.10.03
Zhang, X.T., Y.C. Liu, Z.Z. Zhi, J.Y. Zhang and Y.M. $\mathrm{Lu}$ et al., 2002. Temperature dependence of excitonic luminescence from nanocrystalline $\mathrm{ZnO}$ films. J. Luminescence, 99: 149-154.

DOI: $10.1016 / \mathrm{S} 0022-2313(02) 00331-9$ 